\title{
Inventário do patrimônio arquitetônico e histórico em Santa Isabel do Sul - Arroio Grande-RS: o caso das edificações institucionais e de socialização
}

SALABERRY, Jeferson Dutra

\section{Resumo}

O presente artigo é resultado do trabalho denominado Inventário do Patrimônio Arquitetônico de Santa Isabel do Sul - Arroio Grande-RS, e trata do arrolamento e registro das estruturas arquitetônicas e urbanas remanescentes e portadoras de valores culturais da referida localidade. Os objetivos centrais do trabalho foram o resgate e o conhecimento/reconhecimento da arquitetura da localidade, tanto em relação aos seus valores estéticos como aos históricos. Como objetivos específicos, procedeu-se a uma descrição histórica da localidade e a um registro e documentação dos antigos prédios remanescentes. A metodologia utilizada é histórica e de inventário, trabalho de pesquisa que exigiu a utilização de diversas técnicas e procedimentos como: levantamento fotográfico expedito, levantamento métrico arquitetônico e preenchimento de fichas de caracterização arquitetônica e contextualização histórica. Os resultados mais importantes do estudo foram: (a) o conhecimento do estado atual de descaracterização em que se encontram as edificações, o qual permite a comparação com diagnósticos anteriores; (b) o conhecimento da organização em planta de todos os imóveis estudados, informação desconhecida até a presente pesquisa. Podemos concluir que a vila de Santa Isabel do Sul apresenta remanescentes arquitetônicos muito significativos pelo seu valor histórico e por identificar edificações que, apesar das descaracterizações e do abandono, são significativas, por serem portadoras dos elementos estéticos da arquitetura característica do período inicial da urbanização do Rio Grande do Sul.

Palavras-chave: Patrimônio. Preservação. Arquitetura. Santa Isabel do Sul - Arroio Grande-RS.

\begin{abstract}
:
This paper stems from the research entitled Inventory of Architectural Heritage of Santa Isabel do Sul - Arroio Grande-RS. It presents the listing and records of local surviving architectural and urban structures that bear the cultural values of the region. The main goals of this work involve recovering and learning about the local architecture, as regards both its aesthetical and historical values. This work's specific goal, in turn, involves presenting a historical description of the location, as well as records and documentation of surviving old buildings. The methodology applied is historically-oriented and the inventory as a research tool requires the use of several techniques and procedures, e.g. expeditious photographic survey, metric architectural survey, and the filling in of records of architectural characterization and historical contextualization. The most relevant results obtained were: (a) knowledge of buildings' current state of decharacterization, which enables comparison with previous diagnoses; (b) knowledge of the plans of all the buildings studied, a piece of information not known prior to this research. It is possible to conclude that the village of Santa Isabel do Sul has architectural remains that are highly significant because of their historical value and - despite their decharacterization and state of abandonment - depiction of aesthetical elements of the architecture that was typical of Rio Grande do Sul's early urbanization period.
\end{abstract}

Keywords: Heritage. Preservation. Architecture. Santa Isabel do Sul-Arroio Grande-RS. 


\section{Introdução}

Poucos distritos têm em sua trajetória uma emblemática e cativante história como Santa Isabel. Envolvida geograficamente pelos caminhos pioneiros no sul do Brasil, estruturou-se dentro dos projetos de avanço português em direção ao Prata, na ocupação dos campos sulinos. Assim, silenciosamente, o distrito foi presença significativa nos acontecimentos políticos e militares que delinearam as divisas e fronteiras no sul do Brasil.

Entre 1882 e 1893, Santa Isabel se emancipou do município do Arroio Grande. Potencialidades e movimentos liberais demarcaram um rumo, uma utopia, alicerçada em um tripé básico: princípios econômicos liberais, produção de bois para as charqueadas e o escravismo pungente nas relações sociais e econômicas estabelecidas na região àquele tempo, no fulgor do século XIX.

A ocupação desse território começa com as vastas doações, pelo governo português, no ano de 1789, de sesmarias aos fazendeiros militares, para a ocupação e proteção das fronteiras. 0 local demorou a se desenvolver como núcleo urbano, mas inevitavelmente estava situado em um ponto estratégico, à beira do canal São Gonçalo (Figura 1), portal de saída ou entrada da Lagoa Mirim. Somente em 1835, na Revolução Farroupilha, foi que se percebeu um contingente semiurbano, em que estavam agrupados militares, escravos, peões de estâncias ou as conhecidas tropas contrabandeadas do Uruguai. $\mathrm{O}$ porto passava a ser o contato, as idas e vindas, o comércio e as esperanças das oligarquias rurais e seus projetos políticos (SALABERRY; MENDONÇA; LÚCIO, 2012).

A presente pesquisa tem como tema a preservação do patrimônio arquitetônico. A delimitação físico-espacial é o distrito de Santa Isabel do Sul (Figura 2), situada no município de Arroio Grande-RS. A justificativa do trabalho está vinculada à emergência da preservação. O distrito de Santa Isabel encontra-se afastado das áreas de desenvolvimento econômico e social. Também é importante destacar que parte significativa da população do local é proveniente de outros municípios, o que resulta na baixa estima desta em relação aos valores da localidade. Os objetivos centrais foram o resgate e o conhecimento/reconhecimento da arquitetura da localidade, tanto em relação aos seus valores estéticos como aos históricos. Como objetivos específicos, procedeu-se a uma descrição histórica da localidade e a um registro e levantamento dos antigos prédios remanescentes.
Figura 1: Canal São Gonçalo, Sangradouro da Lagoa Mirim.

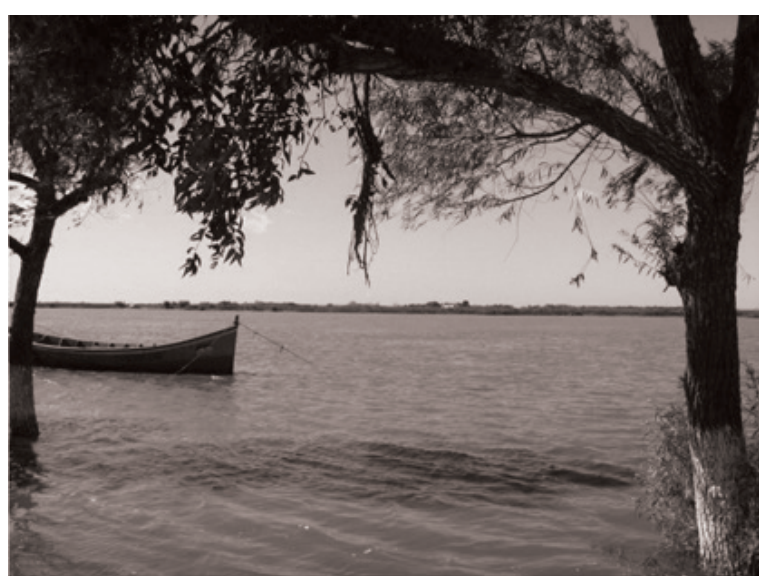

Fonte: Salaberry; Mendonça; Lúcio, 2012.

A metodologia utilizada é histórica e de inventário, trabalho de pesquisa que exigiu a utilização de diversas técnicas e procedimentos como: arrolamento e registro das estruturas arquitetônicas e urbanas com levantamento fotográfico, levantamento métrico arquitetônico e preenchimento de fichas de caracterização arquitetônica e contextualização histórica (BLOCH, 2001).

\section{Contextualização Histórica}

Em 1865, durante a viagem a Jaguarão, D. Pedro II foi visitar a nascente Vila de Santa Isabel, episódio a que o Conde D’Eu (1981) fez referência em suas Memórias Militares. Naquele tempo, sua Igreja já estava benta; o terreno para a construção da igreja foi doado em 1859 e as obras concluídas em 1861. Movimentos no porto, produtos importados do Uruguai, contrabando conveniente, e nos empórios da Vila o vinho do

Figura 2: Mapa do Brasil e Rio Grande do Sul e Mapa Hidroviário localizando o porto de Santa Isabel do Sul.

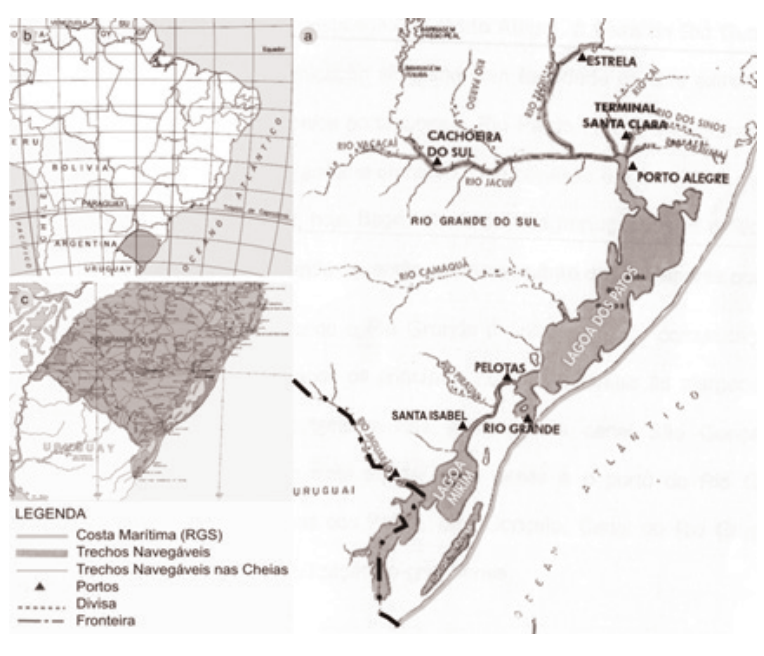

Fonte: Salaberry, 2012. 
Porto, sabonetes Alvat, munição, tecidos de seda e anis fomentavam a rede do comércio que subia a serra até Arroio Grande (MENDONÇA, 2002).

As queixas contra Arroio Grande e o descaso de sua administração cresceram. Os novos sopros liberais e movimentos de emancipação irremediavelmente sairiam dos fuxicos interioranos para converter-se na mais importante experiência emancipatória do extremo sul. Em 9 de maio de 1882, com a Lei Provincial 1.368, foi criada a Vila de Santa Isabel. As eleições para vereadores ocorreram em $1^{\circ}$ de julho de 1882 e o Auto de Instalação ocorreu no dia 27 de janeiro de 1883 (MENDONÇA, 2002).

A arrecadação da Vila girava em torno de impostos taxados das exportações de gado, olarias, caieiras, casas de comércio e arrematações dos Passos dos Canudos, Maria Gomes e Orqueta. Com percentuais menores, apareciam as ferrarias, carpintarias e mascates. Não era tipicamente um município rico, mas as principais dificuldades estavam nos constantes embates com Arroio Grande, que não aceitava a perda de seu ex-distrito.

Com a queda do Império e a chegada da República em 1889, novos e fortes rumores circulavam e atormentavam a Junta Municipal. Depois das rixas ao longo dos anos, agora os liberais sairiam de cena da vida política e uma nova batalha se avizinhava. Arrastou-se até 1893, quando o Ato $n^{\circ} 11$ de 16 de janeiro, com a rubrica já preestabelecida de Julio de
Castilhos, Presidente do Estado, suprimiu o município isabelense, que lhe fora infiel politicamente (MENDONÇA, 2002).

Novos tempos começaram. Santa Isabel voltou a ser distrito e os antigos prédios públicos ficaram vazios. Viriam, ao mesmo tempo, a Revolução Federalista e os caminhos flancos aos revolucionários de Gaspar Martins e Gumercindo Saraiva. Desordem social, vândalos, oportunistas, abandono e despreparo das forças policiais e processos de migrações forçadas caracterizaram a curta resistência que Santa Isabel poderia oferecer. Restaram frágeis raízes que vêm se perdendo ao longo do tempo, além do desconforto de não serem reconhecidos os herdeiros da antiga Santa Isabel.

\section{As edificações do Distrito de Santa Isabel}

Entre as construções remanescentes da localidade, o grande destaque é a Capela localizada ao centro do povoado (Figura 3). Destaca-se pelas suas qualidades morfológicas e valor artístico de sua arquitetura (tipologia, estilo), pois suas características expressam o "ponto alto" da arquitetura religiosa do século XIX, característico dos vilarejos em seu período inicial de urbanização na fronteira sul do Rio Grande do Sul. Atualmente a capela se encontra em razoável estado de conservação e principalmente em adequada situação de preservação das características originais.
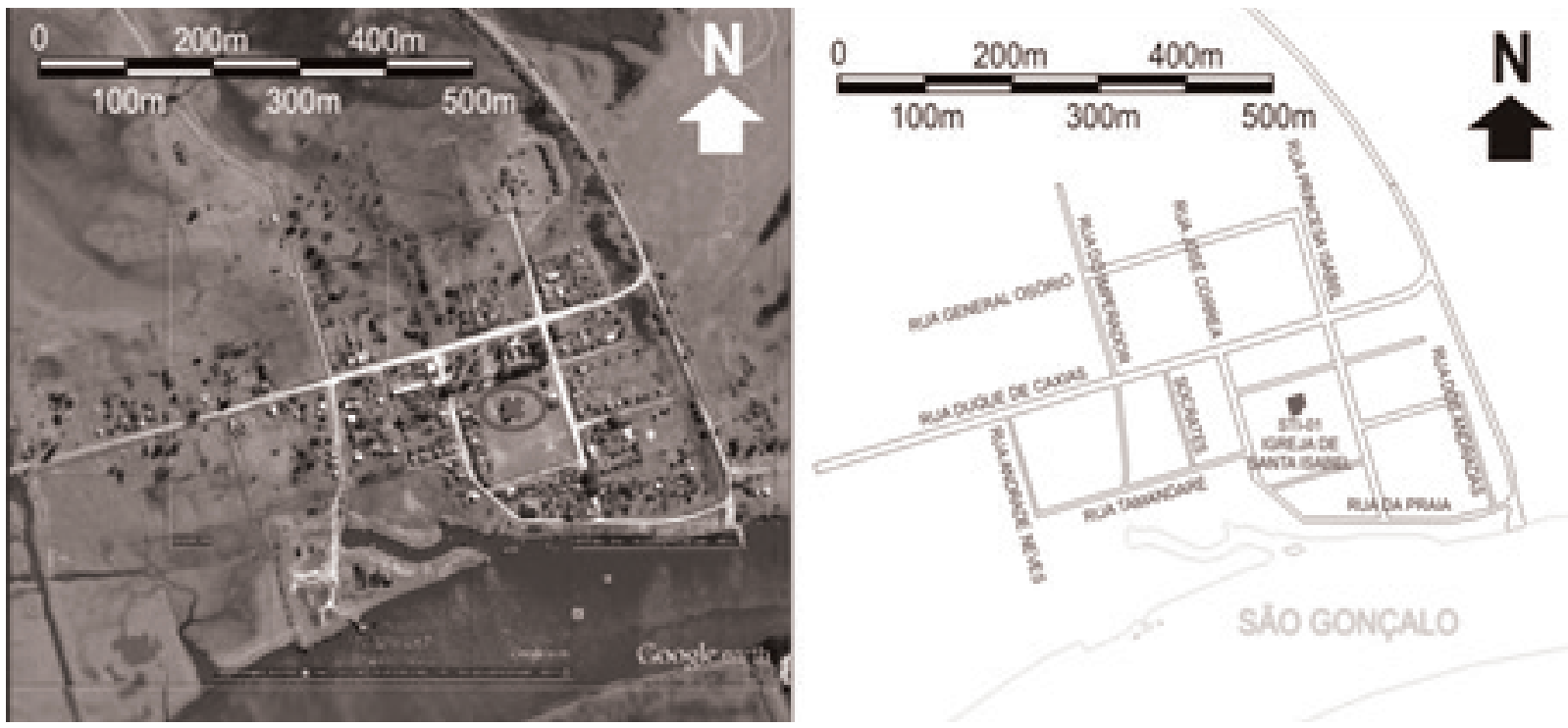

Fonte: Mapa elaborado pelo autor tendo como base o Google Earth. 
Figura 4: Capela de Santa Isabel.

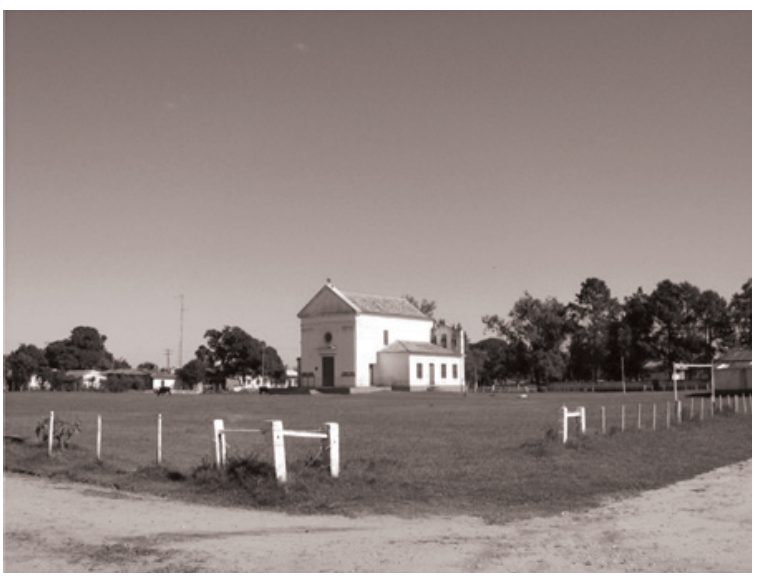

Fonte: Salaberry; Mendonça; Lúcio, 2012.

A nave da capela é coberta com telhado capa-canal em forma de duas águas, sendo na fachada principal delimitada por frontão triangular ornamentado com cornija e cimalha e a fachada posterior caracterizada por empena cega. A fachada principal é de inspiração Palladiana e, apesar da pequena dimensão, lembra a importância compositiva das pilastras de San Giorgio Maggiore, em Veneza. O conjunto de pilastras monumentais é o principal elemento ornamental, ocupando toda a superfície entre o umbral da porta e o limite da fachada. Também merece destaque a rosácea instalada sobre a única porta da fachada principal (Figura 4).

A volumetria da igreja é constituída de mais dois volumes, sendo estes destinados ao batistério e outro à sacristia. O batistério é um espaço com planta quadrada de dois metros de lado, com seus limites externos chanfrados, situado na lateral esquerda e recuado em relação à fachada principal. A cobertura deste pequeno compartimento é uma pequena cúpula coberta em azulejos portugueses (Figura 5).

O volume designado de sacristia consiste em dois compartimentos, sendo o menor utilizado como local de guarda ou de apoio para as atividades religiosas. As fachadas da sacristia se destacam dos volumes descritos anteriormente, por apresentarem características compositivas, assim como base, corpo, cimalhas, vergas, molduras que não se diferenciam dos elementos arquitetônicos utilizados na arquitetura das demais construções urbanas, exceto a parede que delimita a fachada posterior, que avança sobre o volume do telhado, vindo a formar uma "torre" sineira. Esta fachada, apesar de compreender a fachada posterior da igreja, é bastante ornamentada, de composição tripartida tanto no sentido vertical como horizontal; possui cornijas,
Figura 5: Fachada Principal da Capela de Santa Isabel, Batistério e Sacristia.

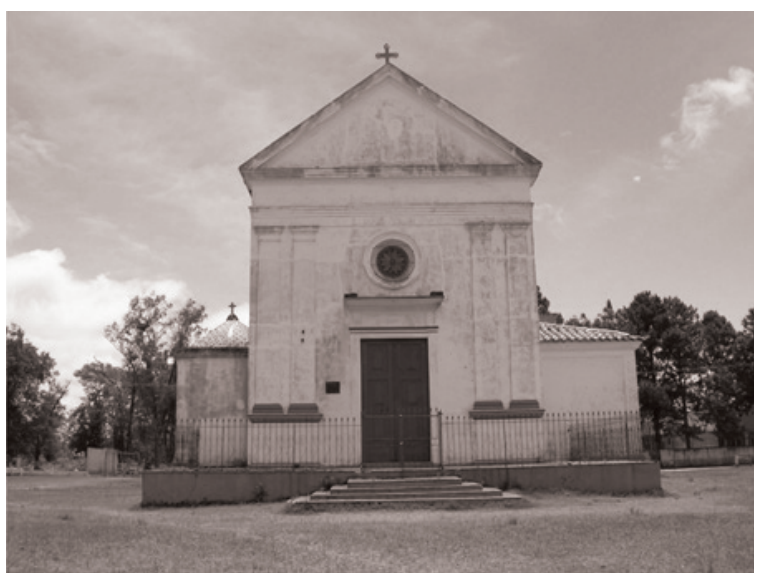

Fonte: Salaberry; Mendonça; Lúcio, 2012.

pilastras, frontão recortado, tudo de forma a compor harmonicamente o conjunto de três sinos (Figura 6).

A igreja, apesar de não representar uma arquitetura monumental, foi construída com os melhores materiais disponíveis na época de sua construção, comparável às igrejas da cidade de Pelotas ou da capital da província. Mas o grande destaque e valor de sua arquitetura é a composição dos seus espaços funcionais, dos seus elementos de composição e de arquitetura, de notável qualidade estética (Figuras 7 e 8).

Figura 6: Fachada posterior da Sacristia.

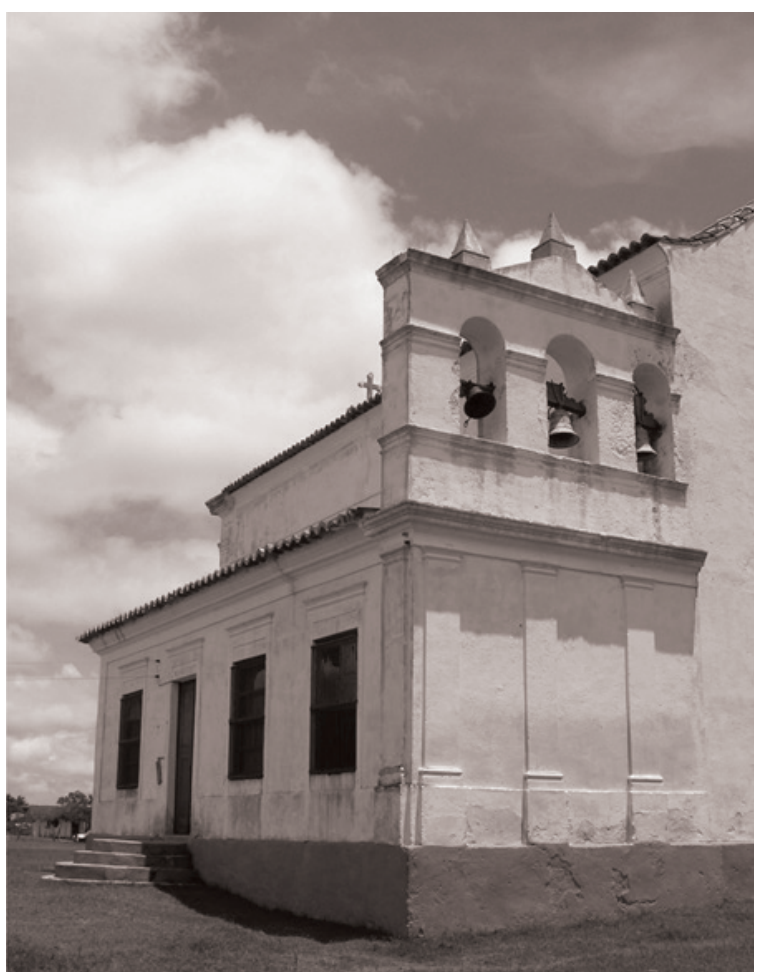

Fonte: Salaberry; Mendonça; Lúcio, 2012. 
A história da capela remonta aos primeiros habitantes do arraial, segundo Arlindo Rupert (1994, p. 253). O Capitão José Corrêa Mirapalheta e sua mulher, Dona Faustina Corrêa, doaram, em 2 de agosto de 1859, uma quadra de terreno com 56 braças de frente e 56 de fundo para que fosse erguida uma capela à Santa Isabel. No lugar denominado Canudos, acima do passo de mesmo nome, à margem do Rio São Gonçalo, onde já havia uma bonita povoação, foi lançada a pedra fundamental, no dia $1^{\circ}$ de novembro do referido ano, pelo vigário do Rio Grande, Padre José Maria Damásio Mattos. Concluída a igreja em 1861, em 3 de maio de 1863, foi benta por D. Sebastião Dias Laranjeiras, que no dia seguinte (4 de maio) celebrou a primeira missa. No mesmo ano (1861), o Comendador Domingos Faustino Corrêa paramentou essa grande e bela igreja. Mais tarde, por desavenças com o capitão Mirapalheta, retomou os ricos paramentos que doara. Pela Lei Provincial $n^{\circ} 586$ de 7 de dezembro de 1866, foi esta capela elevada à Paróquia. Por Provisão do Diocesano de 16 de fevereiro de 1882, foi canonicamente instituída, sendo designado para ela o Padre Antônio Troccoli (1882-1889) (MENDONÇA, 2002).

Atualmente o Bailão Vento Sul, hoje juntamente com a associação comunitária, a escola estadual e a capela, forma o conjunto de espaços de socialização, que além de atender às demandas da comunidade é o ponto de referência para uma extensa área rural.

No dia 8 de janeiro de 1882, nas festividades de instalação do município, animava a festa a Banda Isabelense, no coreto da Praça Aliança. À noite, a aristocracia rural, brancos pobres e negros livres dividiam os espaços no "Salão de Bailes da Vila". Nada de classes misturadas, mas na noite animada com lampiões a querosene,
Figura 7: Capela de Santa Isabel.

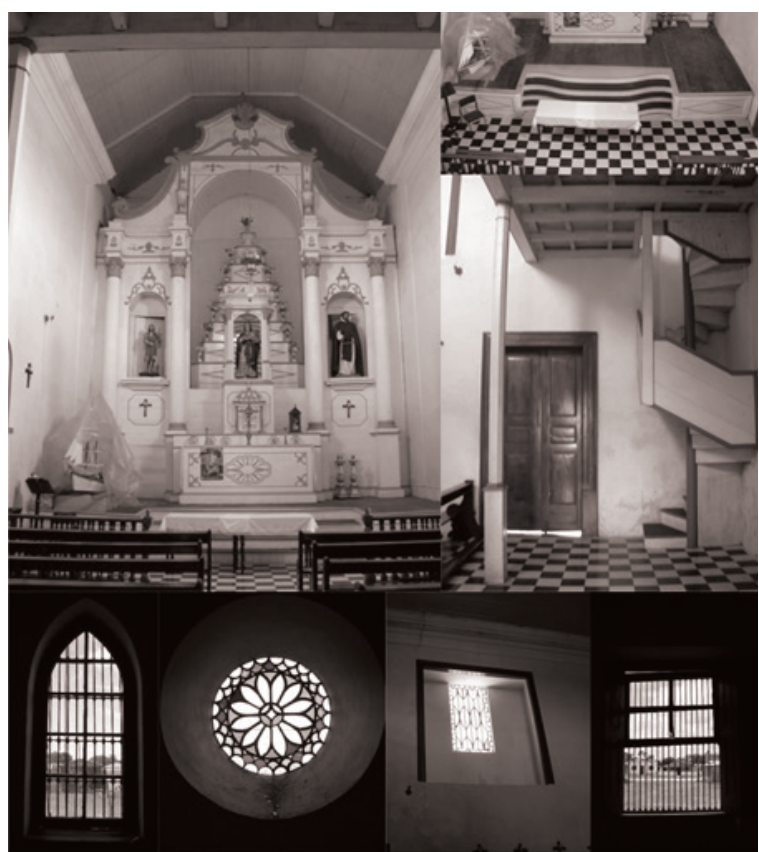

Fonte: Salaberry; Mendonça; Lúcio, 2012

nas ruas da Vila, a alegria da emancipação (MENDONÇA, 2002).

Com relação à história da referida edificação de bailes não foram encontrados dados históricos específicos. Pode ser que se trate do mesmo salão de bailes ou não. Não se identificaram outras citações nas fontes primárias, entre o período de sua construção, na segunda metade do século XIX e o início do XX. A partir da segunda metade do século $X X$ efetivamente a edificação funcionou como espaço de lazer na região. Funcionou como cinema, de propriedade de Enedino Costa, por longa data. A partir dos anos 1880 transformou-se definitivamente no atual salão de bailes (Figura 9).

Figura 8: Interior da Capela de Santa Isabel.
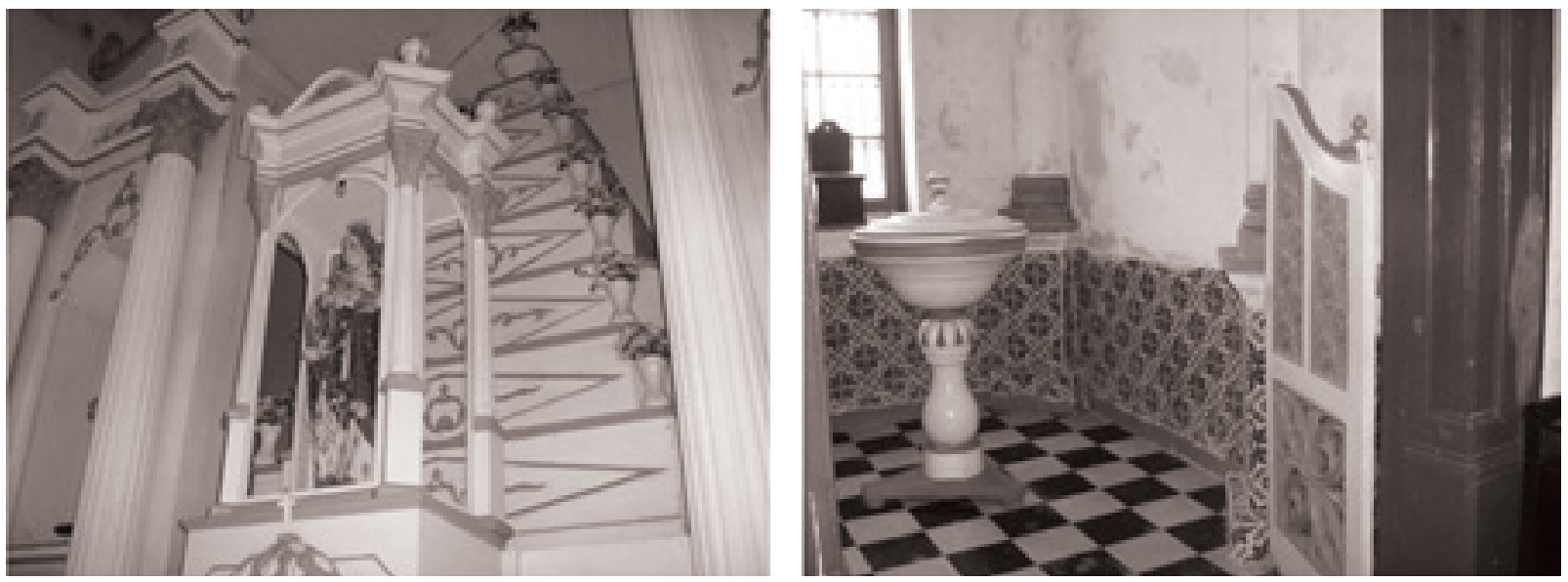

Fonte: Salaberry; Mendonça; Lúcio, 2012. 
Figura 9: Bailão Vento Sul.

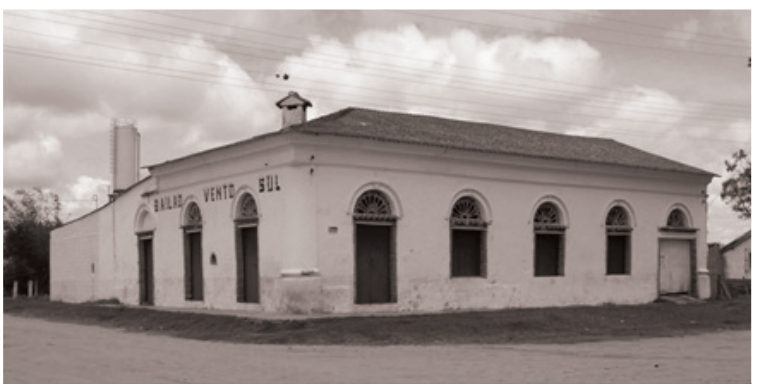

Fonte: Salaberry; Mendonça; Lúcio, 2012.

Com relação a sua arquitetura, podemos destacar a composição da fachada subdividida em: base destacada do corpo, corpo com portas e janelas emolduradas e com verga de arco pleno e coroamento com cimalha e beira. Atualmente o prédio encontra-se bastante alterado - parte da construção antiga ruiu e posteriormente foi remodelada, tanto no seu interior como no exterior. Suas fachadas posteriores e cobertura sofreram muitas modificações. Apesar das mudanças, este prédio de socialização da comunidade é bastante significativo e com estrutura remanescente de elevado valor arquitetônico.

Com relação ao prédio da cadeia, não restou nada mais do que ruínas de uma das celas da prisão. Foi inventariado, não por seu valor artístico, mas pela informação histórica, assim como para registrar e divulgar que não apenas os prédios históricos de utilização privada são demolidos, mas também os prédios públicos (Figura 10).

A construção da cadeia fez-se necessária com a criação da Vila, assim como a organização policial e de juízes. Foi constatada a utilização do referido prédio em 1885 . O primeiro delegado foi empossado no dia $1^{\circ}$ de agosto de 1883 , tenente Cecílio Machado da Costa. O delegado seria demitido em 7 de agosto de 1885 e não teria, por bom tempo, autoridade policial e prédio que servissem à Delegacia. Na ata 158 (cópia), de 23 de fevereiro de 1886, da Câmara de Vereadores da Santa Isabel, no ofício do Balancete do ano de 1885 , nas despesas, constam luzes e melhoramentos da Secretaria de Polícia e Cadeia. Em 24 de maio de 1886, em ofício à Assembleia Provincial, o delegado reclama da falta de auxílio, ao que a Câmara responde dizendo do esbanjamento com querosene, papel e tinta (MENDONÇA, 2002).

Com relação às construções de uso público também pode ser destacada a antiga subprefeitura, atual cooperativa de pescadores (COOPESI). Esta edificação faz parte de um conjunto de várias outras residências, em quarteirão denominado "Alto do Bronze", constituindo, de certa forma, a base da estrutura administrativa e de serviços públicos do distrito, a partir do século XX: Subintendência, depois Subprefeitura, Posto de Controle Naval da Marinha e Central Telefônica nos anos 1880. Na década de 1890 voltou a ser a sede da Subprefeitura de Arroio Grande.

Essas edificações compõem o eixo histórico-arquitetônico de Santa Isabel da fase intermediária da ocupação urbana, ou seja, com fachadas planas, com vergas retas, elementos geometrizados (Figura 11), diferentes das construções mais antigas das vergas em portas e janelas, com arcos plenos, com cimalhas e molduras ornamentadas.

Com relação à arquitetura deste conjunto, somente pode-se identificar que algumas das alvenarias são remanescentes das antigas edificações, especificamente o lote em que funcionava a antiga subprefeitura. Nenhum elemento arquitetônico é identificável como autêntico.

Ao analisar as condições de preservação, comparando com o inventario de 1994, verifica-se

Figura 10: Ruína da antiga cadeia de Santa Isabel do Sul.
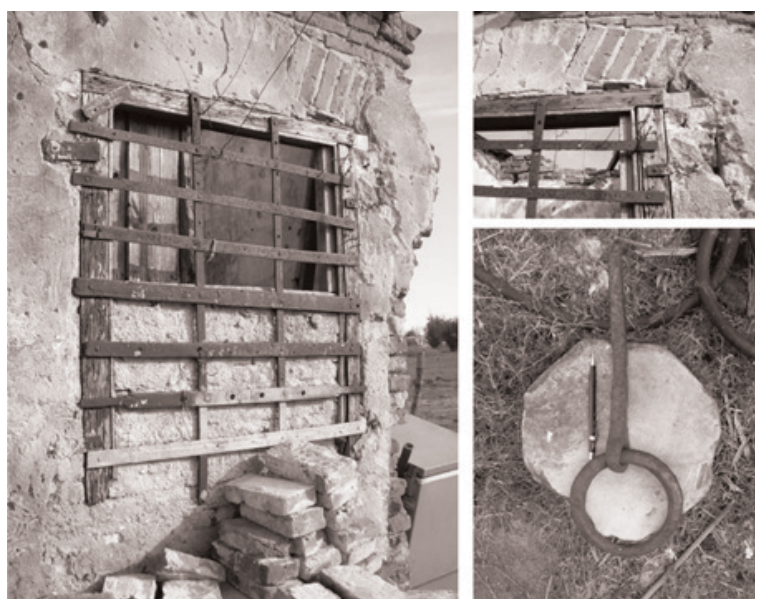

Fonte: Salaberry; Mendonça; Lúcio, 2012.

Figura 11: Conjunto Arquitetônico "Alto do Bronze".

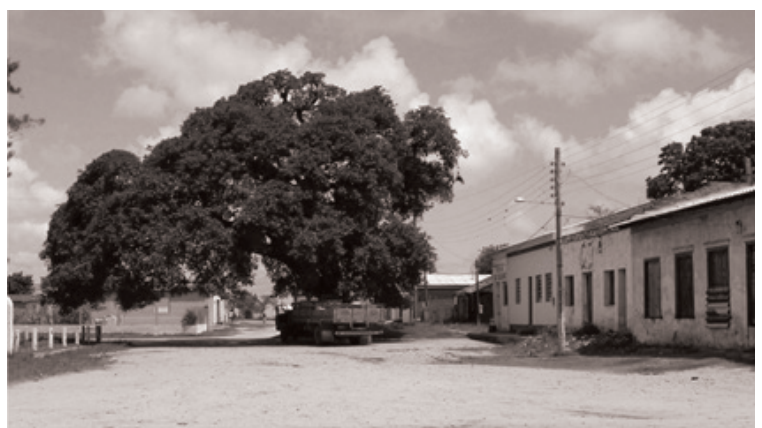

Fonte: Salaberry; Mendonça; Lúcio, 2012. 
que um grande casarão do conjunto foi completamente demolido. Os demais que já se encontravam com alguma alteração. Hoje estão muito modificados. Um deles encontra-se em situação de ruína.

A Rua José Correa Mirapalheta, em que está situado o conjunto "Alto do Bronze", já consta em documentos públicos em 1869. Antes da construção do aterro da rodovia RS-473, eram provavelmente esta rua, a Rua Princesa Isabel ou a Rua do Imperador, onde também estava localizada a cadeia, as principais vias da localidade. É por meio de uma destas três que se dava o acesso para o a área rural e a cidade de Arroio Grande.

\section{O Patrimônio Arquitetônico}

O patrimônio arquitetônico de Santa Isabel vem sendo estudado há algum tempo, como pode ser verificado no "Relatório de avaliação do valor histórico visando propostas de preservação da Vila de Santa Isabel do Sul", elaborado no decorrer do ano de 1994 e coordenado pelo professor Rogério Gutierrez Filho, da Faculdade de Arquitetura/UFPEL, que estudou ao mesmo tempo questões ambientais e patrimoniais de Santa Isabel (GUTIERREZ FILHO, 1994).

Quase uma década depois, com autoria do então deputado Bernardo de Souza, foi aprovada a Lei 11.585 de 12 de janeiro de 2001, que declarou "integrantes do Patrimônio Cultural do Estado conjuntos urbanos e edificações [...]", mencionando, no inciso $\mathrm{VI}$ do seu artigo $1^{\circ}$, a "[...] área histórica da Vila de Santa Isabel do Sul, sede do Distrito do Município de Arroio Grande [...]", com suas delimitações. A lei tinha por objetivo a preservação da história e da arquitetura do lugar (RIO GRANDE DO SUL, 2001).

Desde os primeiros estudos, houve o reconhecimento do valor estético, arquitetônico e histórico do lugar. Também é importante destacar o histórico das condições de abandono em que se encontra o conjunto arquitetônico de Santa Isabel. Segundo o relatório de 1994, a sede do distrito encontrava-se "em condições precaríssimas de desenvolvimento econômico, contendo uma população de baixa renda, habitando um espaço urbano que se encontra praticamente em ruínas" (GUTIERREZ FILHO, 1994, p. 3).

\section{Considerações Finais}

Atualmente, podemos facilmente verificar a pequena eficácia que teve o arrolamento do patrimônio e também da lei que declarou a vila como integrante do Patrimônio Cultural do Estado do
Rio Grande do Sul. Apesar do conhecimento do valor cultural e também da proteção de um instrumento de preservação, ambos não tiveram efeito prático sobre a conservação das antigas edificações. As edificações centenárias são demolidas, abandonadas, subutilizadas e ficam sem manutenção.

Recentemente, a Prefeitura Municipal de Arroio Grande passou a investir na preservação do patrimônio de Santa Isabel, através do Inventário do Patrimônio Arquitetônico de Santa Isabel do Sul - Arroio Grande-RS e também da promoção de dois seminários de preservação, visando, assim, proporcionar o desenvolvimento econômico e social dos moradores da localidade.

Ao realizarmos o Inventário do Patrimônio Arquitetônico de Santa Isabel do Sul, percebemos que essas edificações mostram o desenvolvimento da arquitetura no final do século XIX, pois a antiga freguesia teve um significativo desenvolvimento durante a segunda metade do século XIX e arrefeceu na última década do mesmo século, ficando os prédios sem maiores intervenções modernizantes durante todo o século $\mathrm{XX}$.

Um universo significativo de edificações não resistiu ao tempo, à ação das águas das enchentes e principalmente à ação do homem. Das poucas edificações que resistiram, algumas não passam de ruínas e não resistirão à situação de abandono em que se encontram. Contudo, as construções remanescentes devem ser mais bem estudadas e terem sua existência material garantida, principalmente a significativa Igreja de Santa Isabel.

Também é importante destacar o grande patrimônio natural que possui a localidade. Podemos observar em algumas fotografias a presença de grandes figueiras convivendo de forma relativamente harmoniosa com as edificações antigas. Ambas devem ser preservadas, já que a Vila de Santa Isabel fica localizada dentro da área destinada a ser uma Reserva Ambiental (Mato Grande).

Espera-se que o inventário, o registro e a divulgação resultem na preservação ambiental, patrimonial; que o conhecimento da história e o desenvolvimento cultural possam ser úteis para o futuro, gerando desenvolvimento econômico e qualidade de vida para a população local. 


\section{Referências}

BLOCH, M. Apologia da história ou o ofício do historiador. Rio de Janeiro: Zahar, 2001.

D'EU, L. F. M. F. G. D'O., Conde. Viagem militar ao Rio Grande do Sul. Belo Horizonte: Ed. Itatiaia, 1981.

GUTIERREZ FILHO, R. et al. Relatório de avaliação do valor histórico visando propostas de preservação da Vila de Santa Isabel do Sul. Pelotas: FAURB-UFPEL, 1994. (Relatório de Pesquisa).

MENDONÇA, C. V. A Vila de Santa Isabel: dignidade de um povo. [S.I.: s.n.], 2002. No prelo.

RIO GRANDE DO SUL. Lei $n^{\circ} 11.585$, de 12 de janeiro de 2001. Diário Oficial [do] Estado do Rio Grande do Sul. Porto Alegre, RS: Poder Executivo, 15 jan. 2001.

RUPERT, A. A história da Igreja no Rio Grande do Sul. Porto Alegre: EDIPUCRS, 1994.

SALABERRY, J. D. História e arquitetura da agroindústria no Bairro do Porto: Pelotas-RS (1911-1922). Pelotas: Editora Universitária/UFPel, 2012.

SALABERRY, J. D.; MENDONÇA, C. V.; LÚCIO, E. C. Inventário do Patrimônio Arquitetônico de Santa Isabel do Sul - Arroio Grande-RS. Pelotas: Jeferson Dutra Salaberry, 2012. CD-ROM. 